Article

\title{
The Essence, Classification and Quality of the Different Grades of Information
}

\section{Kun Wu}

International Center for the Philosophy of Information, Xi'an Jiaotong University, Xi'an 710049, China; E-Mail: wukun@mail.xjtu.edu.cn; Tel.: +86-133-9928-4026

Received: 6 June 2012; in revised form: 27 August 2012 / Accepted: 30 August 2012 /

Published: 10 September 2012

\begin{abstract}
I define information from a philosophical perspective as a category that indicates the presence of indirect existence, which is a self-display by material entities (with direct existence) of the status and trajectory of that existence. In this paper, based in part on articles published only in Chinese over the last 30 years, information is shown to include three basic forms: In-itself, for-itself and regenerated information, which is constituted by the first two. Information in these three basic forms establishes the essence of information which is further developed in a fourth form-social information. Information is further characterized by the qualities of its three different grades, corresponding to these forms: The quality of first-grade information demonstrates direct objective existence and indirect objective existence; the quality of second-grade information demonstrates multiple levels of direct objective and indirect objective existence; the quality of third-grade information is that of the subjective relationships in human understanding that are encoded as information. The grounding of information in the ontological structure of the world gives it a central role in the approach to knowledge, constituting a new and necessary critique of the classical separation of the academic disciplines and the bases of modern philosophy.
\end{abstract}

Keywords: direct; existence; field; indirect; information; essence; grade; level; form; quality

\section{Introduction}

The problem of the essence of information is a major theoretical issue in information science, systems science, and philosophy. Prior research on the ontology of information has looked at information only from the point of view of its (simple) existence. The new concept of ontology to be 
presented here, of information as an evolving process, has been developed in a series of papers published in Chinese in the period 1981-2012, and available in part in English only since the Conference on the Foundations of Information Science that took place in Beijing in 2010 [1]. It is worth mentioning that in 2011, two presentations and an evaluation of the results of my studies of the philosophy of information were published in English: J.E. Brenner's article Wu Kun and the Metaphilosophy of Information [2] and Li Guo-Wu's Information Philosophy in China: Professor Wu Kun's 30 Years of Academic Thinking in Information Philosophy [3].

The most important innovation of my theory is a new segmentation of the field of existence (the extant domain) in informational terms that leads to a new world view, a new existential picture of world. Thus, in order to explore the essence of information, it is necessary to first examine the scope of the field of existence itself - the existential field. While not frequently used in Western philosophy and science today (except in some limited areas of sociology), the concept of an existential field will be a familiar one to students of, for example, A.N. Whitehead [4].

I should perhaps add, for those readers who might be nervous about my use of the term "essence" in regard to information, that it is still very much in current use in philosophy and logic to indicate different forms of existence and different identity conditions for objects and properties.

\subsection{Shortcomings of the Traditional Division of the Existential Field}

"Existence" is a broad, general designation for all things and phenomena in the world. All forms of philosophy attempt to deal with questions about the origin of world, but they do not make a clear statement of the scope and composition of existence as a field. Theories have been produced with a wide variety of correlations according to the way in which the existential field is divided, leading to endless debates about what constitutes a ontology and its hierarchical structure. In fact, it is rather disconcerting to note that in order to approach correctly a concept that is considered part of standard science-information - we must in fact reexamine the entire philosophical structure of transmitted human knowledge.

In its definition of the existential field, traditional philosophy has had one basic tenet: The entire world can be divided into two main areas of matter (mass-energy) and mind: Therefore, existence $=$ matter + mind. If, according to the definition of modern materialism, matter is regarded as objective reality, then the corollary to be drawn is: objective reality $=$ objective existence $=$ matter.

However, it has proven difficult to transfer to the domain of information this doctrine of the entire field of existence as being composed by its components of matter and mind, plus the inference that objective reality $=$ objective existence. I will prove my view in the following discussion.

\subsection{A Logical Division of the Existential Field}

The first step in our approach is to apply some of the principles of basic bivalent propositional logic to the terms of interest. Let us define that objective $=\mathrm{P}$; real $=\mathrm{Q}$. Then, the antithesis of objective- "subjective" is -P (read "non-P"), and the antithesis of real-"unreal" is -Q (read "non-Q"). We then construct a conjunction expressing the pair-wise combination of these four propositions, obtaining the following six logical formulas: 


$$
\mathrm{P} \wedge \mathrm{Q} ; \mathrm{P} \wedge-\mathrm{Q} ;-\mathrm{P} \wedge \mathrm{Q} ;-\mathrm{P} \wedge-\mathrm{Q} ; \mathrm{P} \wedge-\mathrm{P} ; \mathrm{Q} \wedge-\mathrm{Q}
$$

Eliminating the latter two as violations of the formal axiom of non-contradiction, we have the remaining four formulas that correspond to the terms listed below:

$$
\begin{aligned}
\mathrm{P} \wedge \mathrm{Q} & =\text { Objective reality } \\
\mathrm{P} \wedge-\mathrm{Q} & =\text { Objective unreality } \\
-\mathrm{P} \wedge \mathrm{Q} & =\text { Subjective reality } \\
-\mathrm{P} \wedge-\mathrm{Q} & =\text { Subjective unreality }
\end{aligned}
$$

Do these four terms have the desired significance as descriptions of the constituents of the universe? Let us analyze them individually.

\subsubsection{Objective Reality}

The term "objective reality" does indeed have a reference. As noted above it is the "matter" of contemporary materialists. To what then does "objective unreality" refer? According to the previously mentioned division of the areas of existence in traditional philosophy, "objective unreality" could not exist, because "objective reality = objective existence", and, as long as an "objective" thing is "real", it cannot be "unreal". However, as we have pointed out, such a tenet has not been developed through any strict scientific or logical argument. No idea or basis of apriority has been established for it.

\subsubsection{Objective Unreality}

We note however Lenin's [5-7] expression of an idea of the nature of objective unreality: All things have similar ways of reflecting other things. The essence of reflection is the capacity and features of something, its "contents", to be reflected in another material thing. This mapping of the contents and features of things obviously cannot be equated with the things themselves, but also cannot be equated with any other mappings of these contents and characteristics. We never say that the reflection of the moon the water and the moon are the same thing. The moon is the objective, real moon; a body exists directly as the moon. The reflection of the moon in the water is also objective, and is beyond human consciousness, independent of man's will, but the moon-in-the-water is not real. It is only the "shadow" of the real moon. While the water as the locus of the mapping or carrier of this shadow or reflection is real, the reflection is not the real moon itself. It is absurd to "fish" for the moon in the water. Like the moon in the water, a flower in a mirror is similar phenomenon, both objective and unreal. In Chinese, the phrase: "The moon in the water, the flower in the mirror" is a popular expression of this perception.

We can easily cite many related, more profound examples. For example, the reality of many years of different growing conditions between summer and winter is condensed in the annual rings of the trees exposed to them; genetic historical relationships are encoded in DNA, as well as the relational processes of individual development; evolutional historical relationships are condensed in stratified geological structures; and even the universe's origin and evolution to the present day is condensed in the correlations between the structural states of the existing universe, and so on. All these entities have an objective albeit unreal nature, and we therefore must include an "objective unreality" within the existential field. To repeat, "objective unreality" refers to or is a title of a corresponding categorial 
feature of reflection between objective things. It is the "trace" of various natural relationships involved in the general mappings and constructions of and in the objective world, that is, a specific coding structure for the storage of the contents of the interactions between matter and things. It is in this particular sense that we say that the modes in which "objective unreality" and "objective reality" exist are both signs of the material world but with a difference of essence.

\subsubsection{Subjective Reality and Unreality}

To what does "subjective reality" refer? A materialistic theory of reflection would say that a subjective thing in the final analysis is a reflection of the subject in the object. Since it is a reflection, then the reflection, that is not the reflected object itself, also cannot be real. This is similar to our view that "reflects" is an existential category involving a relation between phenomena in general. So the concept of "subjective reality" of phenomena actually refers to nothing. "Subjective unreality", on the other hand, clearly refers to a person's conscious mental phenomena which are the resultant of his or her conscious cognitive processes, which being subjective, are unreal for others, but they are objectively unreal for the person.

\subsection{The Re-Segmentation of the Existential Field}

From the above analysis, we can draw a preliminary conclusion: All the "existence" in the whole universe (the world, nature) can be put into the categories of objective reality, objective unreality and subjective unreality as its three major divisions. The scope of objective existence is thus broader than objective reality (matter). The material category does not include the entire mental "world". There is a field of "objective unreality" between the material and mental to which traditional science and philosophy have not paid adequate attention, even when it is given a physicalist interpretation [8].

The mind (subjective existence) and "objective unreality" have a common "unrealistic" essence. The entire existential field can be divided into objective and subjective, but also it can be divided into real and unreal. Because only objective reality is real, the categories of the real and the material both possess the features of and are fully consistent with connotation and extension. If we do the analysis starting from the correlation between the real and the unreal, then we are more likely to obtain a correct picture of the relations between the material category and the categorial domain of the world that is outside it.

To repeat our example, we said that there is a moon in the sky, and there is a moon in the water. The moon is real; the moon in the water is unreal. The existence of the moon-in-the-water is a consequence of the existence of the moon, the former is the latter's "shadow". In this way, we have established a correspondence correlation between the real moon and the unreal "moon". Starting from this correlation, we can completely characterize the term moon and its two referents: The real moon is called the direct existential moon and the unreal moon is called the indirect existential moon.

In this way, we have shown that we can take real and direct existence as concepts of the same level, and unreal and indirect existence as concepts of the same level. From the point of view of indirect existence, indirect existence is a reaction (in the broad sense) to direct existence. From the point of view of direct existence, indirect existence is a display of direct existence. The reflection in consciousness of the direct existential object outside consciousness is a replication and knowledge of 
this object in consciousness. Therefore, in the final analysis, subjective existence is an indirectly existing reflection of direct existence. Direct existence is a domain that we relegate to the material category, but indirect existence can be related to the concept of "information" in modern science (this point it will be discussed in detail in the next section).

Based on the above, we list the following four new expressions of the ontological relationships involved:

(1) Matter $=$ objective reality $=$ reality $=$ direct existence;

(2) Unreal = objective unreality + subjective unreality (mind) = indirect existence = information;

(3) Objective unreality = objective indirect existence = objective information;

(4) Subjective unreality $=$ subjective indirect existence $=$ subjective information.

According to these four expressions, we construct the following diagram of the division of the existential field (Figure 1).

Figure 1. Diagram of the existential field [9].

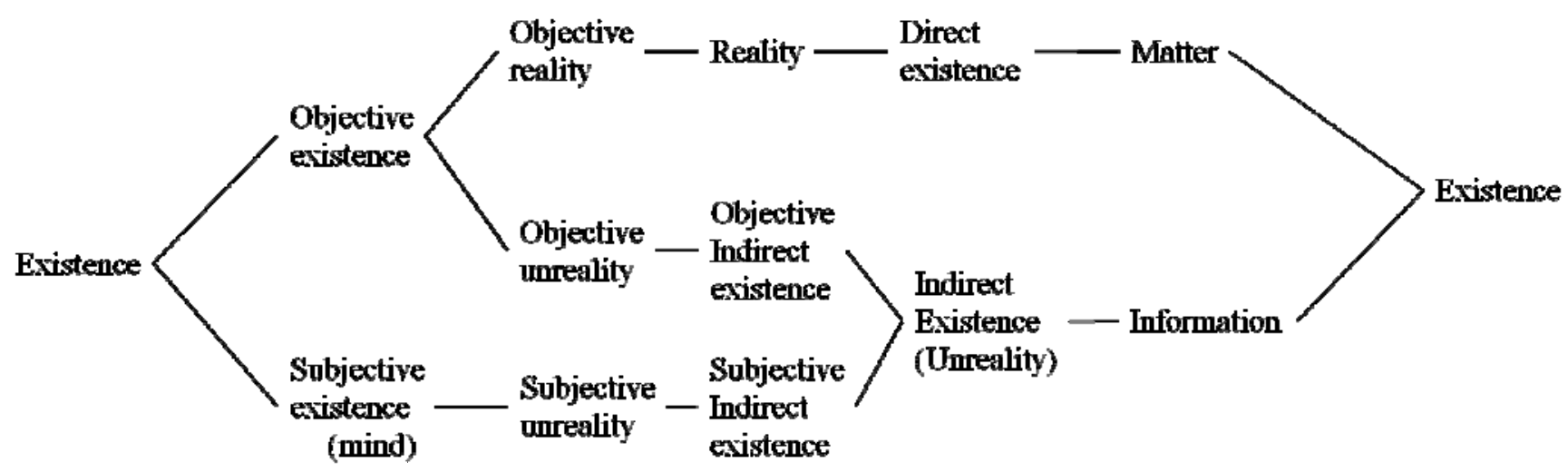

From Figure 1, we can clearly see how information "forces" the mental and material existential field to divide in such a way as to give a place for it, how mental phenomena are essentially regulated by information.

\section{Defining the Essence of Information}

We said above that the world and all the things in the world are a unity of direct and indirect existence, which includes provision for the indirect existence of the informational world. It is thus critical to explore the informational essence of the metaphysical problems that this indirect existence entails.

The analysis of existing explanations distinguishes at least three different levels in the concept of information: First, the level of understanding of people's everyday experience; second, the practical level of information science and technology; and third the philosophical level.

\subsection{The Common Experiential Understanding of Information}

In daily life, information refers to the content that is revealed or reflected in news, data, images and written or spoken language, etc., with more or less new content. If we understand "message" in the broad sense, looking on informational carriers of all forms as "news", then the true meaning of the above 
definition is: Information is primarily if not entirely the new content of the message. Clearly, this definition applies whether the message can bring to its recipient the meaning of that new content or not.

This commonsense experiential understanding of the concept of information has a comparative and functional role. However, such concepts do not provide (and cannot be interpreted as) the essence of what information is. Although this understanding is linked to certain functional definitions of the concept of information in practical information science and technology, there is a big difference between them and the definition of concept of information in philosophy.

\subsection{The Concept of Information in Practical Information Science}

There is a multitude of definitions of information in practical information science. These definitions are far from being uniformly and universally accepted, but two are perhaps the most influential, and the other definitions can more or less be obtained by deduction from them. I introduce here one version of them for further discussion.

\subsubsection{Information Is the Uncertainty That has Been Eliminated}

This definition is based on that of Shannon, the founder of communication information theory. The meaning is that prior to receiving a communication, there is an uncertainty in its recipient, and after its reception, his understanding of the new contents of the communication eliminates all or part of the original uncertainty.

To different receivers, the same communication will have different consequences; thus, the amount of uncertainty eliminated will also be different. The more new knowledge is provided, the greater the amount of information and the greater the uncertainty removed. A message without new knowledge cannot eliminate any uncertainty, and its informational amount is 0. From this discussion we can clearly see that the definition: "Information is the eliminated uncertainty" is in fact a definition of a relative amount of functional information from the point of view of the information receiver.

\subsubsection{Information as Negative Entropy}

As is well known, Norbert Wiener focused on explaining the meaning of negative entropy of formation in physics according to the 2nd Law of Thermodynamics: Entropy corresponds to the level of uncertainty or confusion of the indicated system. The elimination of uncertainty means a reduction of entropy, so the information can be called negative entropy. Thus it can be derived that "information is the indication of the degree of organization of the system (or, in an orderly nature, its natural order)". From the above two definitions of the essence of information, we can see that pragmatic information theory provides the relativity, functionality and quantization characteristics of information. Although such provisions in the scope of pragmatic information theory have great practical value, they have difficulty in demonstrating the essence and significance of information and its characteristic of universality in nature. 


\subsection{The Concept of Information in Philosophy}

To overcome the narrow conception of information provided in pragmatic information theory, many scientists and philosophers have tried to summarize the essence of information from a philosophical perspective [10]. For a more philosophical interpretation of the issue of the essence of information, one starts with the existing interpretation of practical information science or philosophy of a simple analogy among categories, for example, the interpretations of information as "the dimension of variation", "the amount of variation", etc. This is a simple analogy with practical information theory of information with a statistical metric. Interpreting information as a "space-time series", "state", in the sense of "organization", "degree of order", etc., is making an analogy by comparing information with the distribution characteristics of its carriers. Another example, taking the interpretation of information interpretation as: "Information is a material general property"; "information is style of material existence"; "information is mental entity's characteristics"; "information is neither physical nor mental but some third state"; "information is the fusion of material and mental components"; "information is the external expression of movement"; "information belongs to the category of material interaction" and so on, is defining information by simple analogy with existing definitions of traditional philosophical concepts.

In the discussion of the issue of the essence of information, it is impossible to proceed either by such simple analogy with pragmatic scientific explanations, or by using its traditional philosophical categorial meanings. I argue rather that the issue of the essence of information requires a philosophical critique. My critique is twofold: On one side is the critique of the philosophy of science, involving the elimination of the limitations of scientific interpretations of information that result in narrow views, enabling philosophy to grasp information in a way that goes beyond the purely scientific approach. On the other side, our critique is of philosophy itself. The intention of this latter critique is to overcome the limitations of the framework of traditional philosophy and its theoretical interpretation of the essence of information, thereby making a philosophical grasp of information into a double critique that goes beyond the approach of old systems of philosophy and traditional forms of analysis.

According to my proposal of the mode in which information exists, information is not a direct material existential form; information develops its own value of existence in the performance, external expression of movement, appearances and the meaning of its characteristics. Information is the form of the indirect existence of the (ontological) features of things.

Material interactions inevitably lead to changes affecting the two aspects of an object's internal structure, namely, its state of motion and its compositional "nature". The "trace" of this change is the reception and storage of information in the object. In this process, these aspects are both the source of information (output information) and at the same time also the recipients of information (input information). The consequent interactive changes generate a specific structural coding. Further inputs and outputs produce structural changes in the coding, so that all material interactions and things become carriers of information and accordingly parts of an informosome (see below).

Because of the universality of material interactions, and also because there is no beginning of matter and time, no material system in the universe can have remained in its original initial state with no interaction with other material systems. In the term I have coined to describe this state of affairs, any object is a self-evolved "informosome" that has condensed all kinds of information about past, present 
and future structures and states. Since it is the material nature of an informosome that the properties of any object constitute a unity of direct and indirect existence, this unity also has the triple property of being the source of information, the carrier of information and the information itself at the same time. As a result, we can see the scope of informational existence: Information and matter coexist. Materialists should thus accept that the term information refers to something that can be completely summed up as material but with its own unique mode and status of existence. Due to internal and external objective interactions, objects constantly radiate and reflect quanta to the external world and in this process send information about the mode and state of their own existence depending on the nature of those quanta and their distribution. This shows that the informational ground that produces and reflects the mode and state of physical existence is in the material world itself, in its own physical movement. It is this physical property, showed by it, that makes this world a knowable world. According to the above analysis, we can define at least three basic levels of informational concepts.

\subsubsection{The Physical Existence of Information as a Property of Matter}

This is in summary the concept of information in the materialistic ontological sense. But this sense does not show the difference between information and other modes of material existence and material properties. So it is impossible to comprehend the unique essence of information if one stops only at this level of description.

\subsubsection{Information Displays the Property of the Mode and State of Material Existence}

This is the concept of information as referring to the content and its mode of existence. This shows the unique nature of information, but it remains a description of the phenomenon of informational processes.

\subsubsection{Information Is the Property by which Matter Displays Itself}

Though this property still remains a description of informational phenomena, it does take into account the movement of the information generated.

\subsubsection{Information Is an Indirect Existential Marker}

This provision describes the relation between informational phenomena and abstract information.

\subsection{The Essence of Information}

The above four-level definition of the concept of information provides a path for us from the philosophical point of view toward a definition of the essence of information, its essential definition. This definition can be succinctly formulated as follows: (1) Information is the marker of the philosophical category of indirect existence [11]; (2) it is the self-display of the mode and state of material existence (direct existence) [12].

The first and second clauses of this definition essentially have the same meaning. The "display" of things must be "indirect existence", while the things of "indirect existence" are doing the "display". However, comparing the two sentences, the former is the more abstract, while the latter sentence can 
be seen as concretization of the content of the former. Therefore, the two clauses of this definition, used in conjunction, establish the essence of information.

Indirect existence can be simply summed up as comprised of three areas: One is the record of objects of their own history (including the relationships that obtained between them); the second one is the various properties of the objects, these properties being direct existential processes at their moment of appearance, but their time is not been shown, as it is only an indirect real existence; the third one consists of the various possibilities for self-change and development. These three indirect existences correspond to the historical, present and future situations. They can be coalesced in the direct existential object with its specific structure and state. The direct existential structure and state of any material object is thus determined by its coalesced indirect existence. For the same reason, it can also be said that any material structure and state is both a mapping and a set of rules governing the evolution of self-past, present and future information. So any object is a direct and indirect existential unity, consisting of both a material body and an informosome.

Consciousness is usually presented as a subjective phenomenon, but for us consciousness is an appearance, a complex or "advanced" form of informational activities. In addition, information can also display symbolic information, which constitutes a multi-level indirect existence and shows the multiple levels of information phenomena that are possible. These define the information of information which enables us to come to know the basis of information itself. It is precisely in this sense of "indirect existence" and "self-display". That information has not only its own existential significance and value at the level of ontological existence theory, but also has existential meaning and an independent value of the difference between cognitive subject and object at the level of the philosophical theory of knowledge.

\section{The Classification of Information}

Based on our philosophical proposals for the essence of information, one can draw up the following chart indicating the philosophical classification of the different kinds of information (Figure 2).

Figure 2. The philosophical classification of information [13].

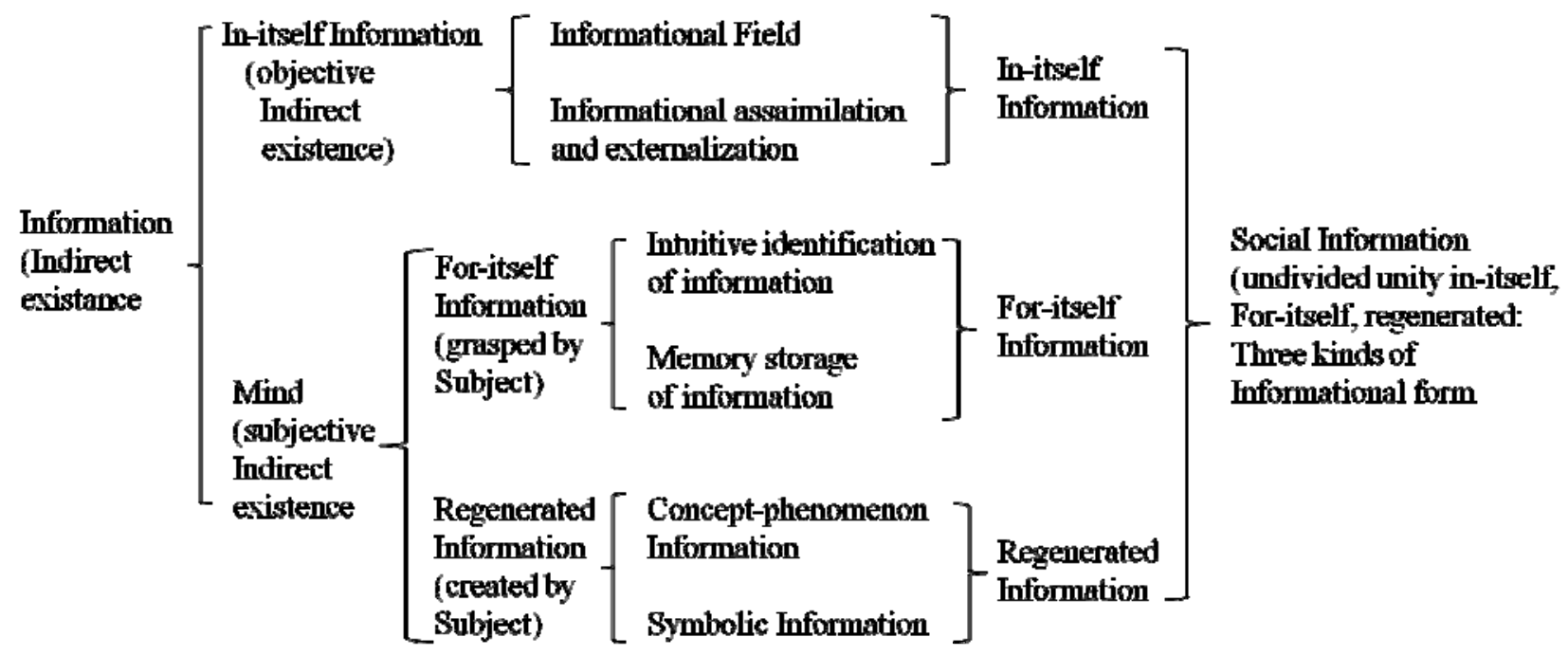


Using the dualities of Figure 2, I make the following remarks: In-itself information is an objective indirect existential marker. It is the original form of information that has not been known or yet acknowledged by a subject. The informational field and the assimilation and externalization of information are the two basic forms of in-itself existential information. The existential field was the original or reflected field of objective particles or fluctuations (matter) of radiation, but any material field according to its particular structure and state displays its own peculiarities. As an emergent source of information, this field, in this sense, is defined as an informational field. Here, the field has dual existential significance and value; it has itself a direct existence and indirect existential unity.

When the information field acts on other matter (recipient of information) it will pass some information from the source contained in the field to the recipient of the information. This is the process of informational internalization (for the recipient of information) and externalization (for the source of information). In the interaction, objects involved the interaction always assimilate or internalize information from the outside and externalize their own information to the outside world. Because any existing object is the consequence (logical and physical) of the interactions between its historical and current states that generated it and that it generates, the internalization and externalization of information, objects themselves become informosomes. Here, as in the case of the informational field, any object also has a dual existential significance and value, as well as a direct and indirect existential unity.

\subsection{In-Itself and For-Itself Information}

In-itself informational activity, where in-itself is defined as in the previous section, is the most fundamental form of information activity; it is the foundation of all other information activities that emerge or develop from it.

For-itself information is the primary form of subjective indirect existence. It is the intuitive grasp by the subject of in-itself information. It includes two kinds of basic forms: Information identification (perception) and memory storage (including emotional memory). For-itself information is the consequence of an animal's psychological activity, which is itself the effect of some kind of information, within a subjective present produced based on in-itself information activities. Obviously, for for-itself information activities to exist there must be biological informational control systems with the capacity of perception and memory as carriers of the information.

\subsection{Regenerated Information}

Regenerated information is an advanced form of subjective indirect existence; it is what the informational subject creates. Its basic forms are concept-phenomenon information and symbol information. Concept-phenomenon information involves thinking in images to create a new image: Symbolic information involves the symbolic characterization of for-itself information and concept-phenomenon information. Human abstract thinking is a complex integrated analytical process for the development of symbolic information based on logical deduction, processing and transformation. In our theory, regenerated informational activities also require informational control systems with thinking capacity (perception and memory) as the carriers of the information. The essence of thought lies in that it is an informational subjective creative activity in the interior of subject 
of thinking through informational processing operations and their results. This informational subjective creative activity is the advanced form of information activities based on for-itself informational processing and transformation. We usually refer to the mind, in fact, a precise informational form of for-itself and regenerated information, as a subjective indirect existence.

\subsection{Social Information}

As noted above, social information is not an independent form of information. It is the comprehensive informational form that emerges from the pattern of relationships among the three kinds of in-itself, for-itself, and regenerated information. Social information is the form of the organic unity of the three-state or tripartite information. In detail, there are three social informational domains: The first is the domain of that part of in-itself information that people recognize and can transform, and the second is the for-itself information that has been regenerated. The third results from the externalization and archiving of regenerated information. The information (including the material and cognitive entities resulting from the organization of information) so created by human beings constitutes cultural information.

The form of cultural information is defined by the carriers of the three independently coded forms of information. For social information to be understood and further transformed by the human subject, his or her knowledge of the content of cultural information must also include the coding of the related in-itself information. Social information is thus the fundamental part of the informational world that has been understood and grasped by the human beings that have created it. In Figure 3, the broken line shows that only a portion of the in-itself, for-itself, and regenerated information achieves this organic unity and achieves the scope of social information.

The full range of informational shapes and forms does not have eternal existential significance and value. Specifically, in-self informational activities exist simultaneously with material activities, which do have objectivity, universality and an existentially eternal nature; for-self informational activities constitute the main mode of psychological activity in animals in general; but it is generally believed that regenerated information refers to the unique conscious activities of human beings, and in some higher animals, some "embryonic" regenerated informational activities. Social information refers only to the cognitive and cultural activities of human social subjects.

Just as the natural material forms have undergone various stages of evolution, natural informational forms have also experienced various stages of evolutionary development. In the evolutionary process from in-itself to for-itself and regenerated information and then to social information, a unity of essence and self-completion is reached. This is the dialectics of the movement of informational form, which one can say that "Nature" has achieved through its own activities and experiences as a "happy" result.

There is thus a material world and three informational worlds: the material world (existing in the mode of matter (substance of the entity) and the field); the in-itself informational world (existing in the mode of an objective informosome); the for-itself and regenerated informational world (existing in the mode of subjective mental activity); and the cultural informational world (existing in the mode of human creational and regenerated external expression and storage of information). Clearly, among these four worlds complex, interwoven interactions exist (Figure 3). 
Figure 3. Complex synthetic picture of the world consisting of a material world and three information worlds [14].

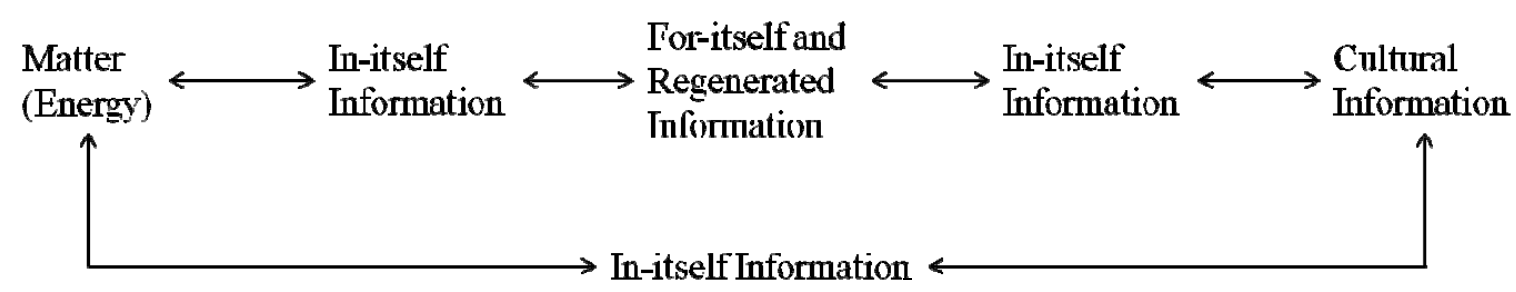

Our synthetic picture of the world is thus multi-dimensional and complex including a material world and three worlds of information, compared with the traditional picture of world constituted according to the two simple principles of material and mental. Popper's proposal of a three-world picture, in our view, does not have an adequate degree of complexity and fails to reveal the world of in-itself information [15].

\section{The Quality of Information-the Informosome}

\subsection{Levels or Grades}

Complex phenomena, both natural and artificial, are perceived to occur in some form of hierarchy constituted by levels or grades. There has been much debate in the philosophical literature about the nature and necessity of the concept of levels. (For a recent discussion of hierarchies, see Salthe [16] and of levels, Brenner [17].) For the description of abstract entities or concepts, the term "level" seems adequate, as it has been used above in reference to ontology. For information, however, as for other natural processes, we consider that "grade" is more appropriate as it also conveys a judgment of quality, perceived or ascribed. (Many foodstuffs are sold to consumers in the United States and elsewhere according to their grade.) In our work, we are very much concerned with the qualitative as well as the quantitative aspects of information. Accordingly, in the remainder of this paper, we will use the term grade when referring to the hierarchy of the types of information that are developed in our analysis.

\subsection{The Nature of Quality [18]}

Further, because it is critical to our ontological approach, we need to define what it means for something, in our case information, "to have a quality". Basically, we endorse a form of strong representationalism [19]. This is the view that a system in a phenomenal state represents a set of objective properties - a "quality" - where both the properties represented and the phenomenon of representing them can be accounted for in physicalist terms. By using such a definition, we provide the necessary bridge to qualitative properties such as "flavor" or "feeling".

In the following discussion, we will therefore consider that the "quality" of a certain level of information is an "informational quality", that is, an aspect of the information associated with a system that is an essential, physical component of it. An obvious consequence of the relation of qualities to different levels of information is that qualities are irreducibly different also. Accordingly, in 1981, I proposed a theory of three qualities of information [12]. The movement of the three-forms of in-itself, 
for-itself and regenerated information attains a unity of essence, such that the quality of information is displayed in the relationships between their different levels, yielding a rich structure of properties of the different grades.

Because of the universal conversion of an object to an informosome, the information field that emerges from (is generated by) the informosome is differentiated historically from its original nature. In this sense, all information fields are the phenomena displayed in the course of the evolution of multi-level informational processes. In view of the multi-level structuring of the information field presented, its having an extremely rich and complex content is inevitable.

\subsection{The Display of Information}

Any object, firstly, is a direct existential object with an internal structure and state, so the object generating the information field first displays its own material direct existence as the content of the first level. However, for all objects that have been involved in information processes (organized, from our philosophical perspective, in the informosome), when their structure and state are shown in the information field, the information contained or condensed in the structure and state, also will be displayed. These condensed informational displays in objects are more indirect than the direct existential display of the objects themselves. Therefore, part of the information is the content of the second level of display in the information field. If we say that the direct existence of a displayed object is the first-level indirect existence of the object in the information field, then the information condensed in the source of information shown in the information field is a multi-level indirect existence of the objects. The condensed information - an indirect existential form of objects - is itself an objective source of information. We take these two informational contents of different levels shown in the information field as defining the quality of the three different grades that information generally has.

\subsubsection{The Quality of First- and Second-Grade Information}

The qualities of the first- and second-grades of information are provided for in the scope of in-itself information. In the field of social information, we will see the quality of another grade of information.

Let us analyze the following event: Apples mature on a tree. A person who knows nothing about an apple's "knowledge" sees just the apple's shape, color; those who know "apple" as a general domain of knowledge will be able to estimate the apple's degree of maturity, the nutrition the tree absorbed from the ground, the process of its growth and development from the apple's form and color, that is, from the same information. Someone may have promised his friend: "When the apples are ripe, I'll call you." Now, enjoying the sight of the ripe apple trees, he is pleased to realize that he can fulfill his promise to his distant friend. The first two of these three contents is the content of quality of two different grades of information indicated above, while the third content is different from the first two contents. It is the individual's subjective processing that gives the information a new content. We designate this new content as the quality of third-grade information.

The quality of first-grade information is at the level of objective appearance for direct existence, which we consider the level of objective indirect existence. In general, we directly perceive content exactly as the quality of first-grade information. The quality of first-grade information is independent of our will, and its rich content goes far beyond the aspects we perceive. What we perceive is only part 
of the quality of first-grade information, but not all. The degree that can be reached is restricted by our capacities of perception.

The quality of second-grade information is the appearance of multi-level objective direct existence, that is, multi-level objective indirect existence. This part of the informational content cannot be grasped simply by our intuitive perception. In order to grasp this part of information, there must be some kind of work done to accomplish its decoding and retrieval. In our view, the quality of first-grade information maps the encoding of the quality of second-grade information.

The richness and depth of the information content that individual humans can decode and retrieve is directly dependent on the structure of the understanding that those individuals have acquired as subjects, that is, the experienced degree of information condensed in them by the materiality of the source information itself. This leads to the inevitable result that the scope of the quality of second-grade of information is related to its cognition by different individuals. The quality of information of a particular grade will always depend on differences of cognition, but this epistemological aspect cannot and should not be separated from its underlying ontological dynamics.

\subsubsection{The Quality of Third-Grade Information}

Thus, when the dynamic role of consciousness is considered in the light of the properties of information and their mutual relations, not taking impersonality for a criterion but taking subjectivity for a requirement, we see the significance of the quality of third-grade information. The quality of third-grade information together with the quality of first-grade of information has nothing to do with reflecting the quality of first-grade information. The quality of first-grade information is only a code, a medium (intermediate) for the transmission of subjective information such as language and writing. The qualities of first-grade information are its sound or shape, while the quality of third-grade information is its shared human properties that give it its meaning. If some language or writing is ungrammatical, then you will only receive its sound or shape, and cannot understand its meaning. The quality of third-grade information in human knowledge is a new quality resulting from the subjective relationships created, and it enables human beings to go outside general information to abstract information, which is a sign of their understanding of it, and further into the general interactions and relationships involved. This quality of third-grade information is revealed in the informational relationships that have been created through the externalization of people's cognitive, social and economic practices. The essence of humanity is the dynamic action of consciousness as a phenomenon that has emerged since the creation of the world.

From the properties of the three qualities of information, we can see that quality of first-grade information is determined by the material source of information, that is, by direct existence itself; the quality of second-grade information is determined by the informational aspects of the assimilation by the human recipient of the material source of information; the quality of third-grade information is determined by the information recipient's teleological properties.

In other words, the quality of first- and second-grade information is the informational nature of objective in-itself existence; the quality of third-grade information is the informational nature of subjective characterization. The quality of first-grade information is so-to-speak the informational protoplasm; the quality of the second- and third-grades is the informational nature of systems. Here, 
we define a system more exactly as a set of objective natural relations and of the relationships between subjective and objective in the case of cognitive processes. The quality of first-grade information is the informational quality of its source. The quality of second- and third-grade information is the quality of the derived information. The quality of second- and third-grade information, in the final analysis, is the result of the objective (or subjective) assimilation of the informational quality of the first-grade, some part of which must be passed on in order to be expressed.

\section{Conclusions and Outlook}

As noted in the Introduction, I have presented here the core thesis of my philosophy of information, namely, its dependence on a conception of reality which, if not totally new, has been obscured by previous philosophical systems that have been dominated by a naive dualist ontology and its classical logic.

In this paper, I have first used aspects of classical logic to resegment the extant domain in terms of its informational components, but I am aware of the limitations of this foundation. Classical logic maintains an artificial separation of the elements of complex processes, especially and including those described by information science. I am also not naïve enough to think that the diagram in Figure 1 is in any sense more than a bare outline of what a philosophy of information should include. For example, as indicated in Section 2. Information is clearly self-referential and a new logical approach, such as that of Brenner in which logic is extended to real processes and which accepts contradictions and inconsistencies, may be the most appropriate [20].

My core thesis is, however, a completely new one: the role and properties of information cannot in fact be correctly discussed without reference to the way in which its properties and characteristics exist by themselves and in relation to others. It is the detailed ontological structure of the world that defines what information is and how it operates or behaves as an operator [21]. Based on the resulting resegmentation of the existential field, one can focus on the different qualities of the three major grades in which information is instantiated.

Beyond this, however, as has been outlined by Brenner in [2], I see far-reaching implications of my philosophy of information for philosophy in general. My new informational view of the need for unification of critical disciplines and their formulation as a metaphilosophy are a potential contribution to a new transdisciplinary paradigm, in which information has a central role in the approach to knowledge and the classical separation of the academic disciplines. In fact, this approach constitutes a new and, in my view, necessary critique of the bases of modern philosophy as a whole.

My Basic Theory of the Philosophy of Information, of which this paper is an integral part, thus provides the ontological basis for the kind of shift of perspective toward a dynamic, qualitative view of information of the kind that Deacon has also called for [22]. In subsequent papers to appear in English, I will describe further the qualitative, normative aspects of information and their implications for ethics and the information society.

\section{Acknowledgments}

I would like to express my appreciation to Wolfgang Hofkirchner and John Collier and Joseph E. Brenner for their multi-faceted support of the project of making my work available in English. I also would like to thank Joseph E. Brenner for our many useful discussions for modifying 
and supplementing this article. Further, the translation of Chinese philosophical terms and phrases into English presents many unique difficulties. I therefore am grateful to Tian-Qi Wu for his translation. Without the unselfish assistance of all of these colleagues, this article could not today be presented to its readers.

\section{References and Notes}

1. $\mathrm{Wu}, \mathrm{K}$. The basic theory of the philosophy of information. Presented at the 4th International Conference on the Foundations of Information Science, Beijing, China, 21-24 August 2010.

2. Brenner, J.E. Wu Kun and the metaphilosophy of information. Int. J. Inf. Theor. Appl. 2011, 2, $103-128$.

3. Li, W.-G. Information philosophy in China: Professor Wu Kun's 30 years of academic thinking in information philosophy. TripleC 2011, 9, 316-321.

4. Whitehead, A.N. Process and Reality, corrected ed; The Free Press: New York, NY, USA, 1976.

5. Wu, K. Objective reality, substance realism, energy doctrine and non-hypostatization of materialism - on the scientific value of Lenin's concept of material objective reality. J. Xi'an Jiaotong Univ. 2004, 24, 69-75.

6. In his Critique of Materialism and Experience, Lenin wrote a two-paragraph discussion of objective unreality: "The only obvious sense in which complex forms of matter (organic matter) can be said to be linked to the materials of which they are composed is that they have similar capacities." "It is logical to assume that all natural materials that have such properties can reflect them."

7. Lenin, V.I. Critique of materialism and experience. In Selected Works of Lenin, Chinese ed.; People's Publishing House: Beijing, China, 1972; Volume 2, Chapter 1, pp. 40-41, 89.

8. Smith, D.W. Mind World; Cambridge University Press: Cambridge, UK, 2004.

9. Wu, K. Division of the Existential Field. Sci. Dialectics Mod. 1986, 2, 32-33.

10. Burgin, M. Theory of Information: Fundamentality, Diversity and Unification; World Scientific: Singapore, 2010.

11. Wu, K. The form of the philosophy of information. Potential Sci. J. 1984, 3, 33-35.

12. $\mathrm{Wu}, \mathrm{K}$. The status and role of information in philosophy. Potential Sci. J. 1981, 3, 53-60.

13. Wu, K. Basic theories of information philosophy and its brand-new breakthrough impact on philosophy. J. Xi'an Jiaotong Univ. 2006, 2, 1-15.

14. Wu, K. Introduction to the Philosophy of Information; Shaanxi People's Press: Shanxi, China, 1987; p. 119.

15. Wu, K. Formal proposal for a unified complex information theory. Stud. Dialectics Nat. 2006, 12, 96-99.

16. Salthe, S. Hierarchical structures. Axiomathes 2012, doi: 10.1007/s10516-012-9185-0.

17. Brenner, J.E. Levels of abstraction; levels of reality. In Knowledge, Technology, Policy; Demir, H., Ed.; Springer: Dordrecht, the Netherlands, 2010.

18. As debated in a recent Symposium, it is clear that there are number of different aspects to information quality but no clear agreement as to what these are. The absence of a clear understanding of qualitative informational quality criteria (such as accessibility, accuracy, 
availability, completeness, currency, integrity, redundancy, reliability, timeliness, trustworthiness, usability, and so forth) results in errors, confusion, impasse, and missed opportunities. Part of the difficulty lies in constructing the right conceptual as well as technical framework necessary to analyze and evaluate such criteria, and to translate them into useful applications. We believe our approach from the side of the philosophy of information has much to offer here.

19. Lycan, W. Representational theories of consciousness. In The Stanford Encyclopedia of Philosophy; Zalta, E.N., Ed.; The Metaphysics Research Lab, Center for the Study of Language and Information, Stanford University: Stanford, CA, USA, 2008. Available online: http://plato.stanford.edu/archives/fall2008/entries/consciousness-representational/ (accessed on 4 September 2012).

20. Brenner, J.E. Logic in Reality; Springer: Dordrecht, the Netherland, 2008.

21. Brenner, J.E.; Burgin, M. Information as a natural and social operator. Presented at the ITHEA International Conference on General Information Theory, Varna, Bulgaria, June 2011.

22. Deacon, T.W. Incomplete Nature-How Mind Emerged from Matter; W.W. Norton \& Co.: New York, NY, USA, 2012.

(C) 2012 by the authors; licensee MDPI, Basel, Switzerland. This article is an open access article distributed under the terms and conditions of the Creative Commons Attribution license (http://creativecommons.org/licenses/by/3.0/). 